\title{
Penjernihan Air Payau Sungai Serdang dengan Limbah Sekam Padi Sebagai Bahan Dasar Zeolit dalam Menurunkan Kadar Logam Besi (Fe) Dan Mangan (Mn) di Kabupaten Tanjung Jabung Barat
}

\author{
Abul Ainin Hapis*, Mukhlis Sanuddin \\ Program Studi Kesehatan Masyarakat, Stikes Harapan Ibu, Jambi, Indonesia \\ *Correspondence email: hapis.ns@gmail.com
}

\begin{abstract}
Abstrak. Abu sekam padi merupakan limbah dari pembakaran sekam padi yang menimbulkan polutan yang dapat mencemari lingkungan sehingga perlu dilakukan pemanfaatan untuk meningkatkan nilai ekonomisnya serta mengurangi dampak buruknya terhadap lingkungan salah satunya yaitu dimanfaatkan sebagai bahan dasar untuk pembuatan zeolit. Penelitian ini bertujuan untuk memanfaatkan limbah abu sekam padi sebagai bahan dasar pembuatan zeolit yang digunakan sebagai adsorben untuk menjernihkan dan menurunkan kadar logam pada air payau. Penelitian ini merupakan penelitian eksperimental. Dimana, penelitian ini dilakukan menggunakan sampel air yang ada di daerah Serdang Jaya Kabupaten Tanjung Jabung Barat, Jambi. Sampel air yang diambil sebanyak 10 liter dilakukan proses penjernihan dengan menggunakan dua cara penjernihan yang kemudian proses penyaringan air dibiarkan selama 30-60 menit sampai air terlihat jernih. Setelah air jernih dilakukan uji kadar logam besi (Fe) dan mangan (Mn) menggunakan Spektrofotometri serapan atom untuk melihat penurunan kadar logam yang ada di dalam air tersebut. Penjernihan air dilakukan menggunakan prosedur terdiri dari air, batu koral, arang aktif, zeolit, pasir dan ijuk. Hasil analisa FTIR menunjukkan adanya gugus fungsi Al dan Si yang terbentuk dari zeolit sekam padi. Hasil analisa XRD menunjukkan terbentuknya struktur-struktur senyawa yaitu Aluminium Oksida dan Natrium Silika. Hasil analisa AAS penjernihan air menunjukkan ada penurunan kadar kekeruhan yang lebih efektif dan penurunan kadar logam Besi (Fe) sebelumnya 2.32 mg/l menjadi sebesar 0,1672 mg/l dan logam Mangan (Mn) sebelumnya $0.0307 \mathrm{mg} / \mathrm{l}$ menjadi sebesar $<0,01 \mathrm{mg} / \mathrm{l}$. Zeolit yang terbuat dari abu sekam padi adalah zeolit $\mathrm{A}\left(\mathrm{Na}_{2} \mathrm{O} \cdot \mathrm{Al}_{2} \mathrm{O}_{3} \cdot 2 \mathrm{SiO}_{2} .4,5 \mathrm{H}_{2} \mathrm{O}\right)$ dan Zeolit dari abu sekam padi dapat digunakan dalam proses penjernihan dalam menurunkan kadar logam Fe 96,71 \% dan kadar logam Mangan (Mn) sebesar 98,23\%.
\end{abstract}

Kata kunci: Abu Sekam Padi; Besi (Fe) dan Mangan (Mn).

\begin{abstract}
Rice husk ash is a waste from burning rice husks which causes pollutants that can pollute the environment so it is necessary to use it to increase its economic value and reduce its negative impact on the environment, one of which is used as a basic material for making zeolite. This study aims to utilize rice husk ash waste as a basis for making zeolite which is used as an adsorbent to purify and reduce metal content in brackish water. This study is an experimental study. Where, this research was conducted using water samples in the Serdang Jaya area, Tanjung Jabung Barat Regency, Jambi. 10 liters of water samples were taken by a purification process using two purification methods, then the water filtering process was left for 30-60 minutes until the water looked clear. After the water is clear, the iron $(\mathrm{Fe})$ and manganese $(\mathrm{Mn})$ levels are tested using atomic absorption spectrophotometry to see the decrease in metal levels in the water. Water purification is carried out using a procedure consisting of water, coral, activated charcoal, zeolite, sand and palm fiber. The results of FTIR analysis showed that the Al and Si functional groups were formed from zeolite of rice husk. The XRD analysis results showed the formation of compound structures, namely Aluminum Oxide and Sodium Silica. The results of AAS analysis of water purification showed a more effective decrease in turbidity levels and a decrease in iron (Fe) levels by $0.1672 \mathrm{mg} / \mathrm{l}$ and manganese (Mn) metal by <0.01 mg / l. Zeolites made from rice husk ash are zeolite A (Na2O.Al2O3.2SiO2.4,5H2O) and Zeolites from rice husk ash can be used in the purification process to reduce levels of Fe metal $96.71 \%$ and metal content of manganese (Mn) amound 98, $23 \%$.
\end{abstract}

Keywords: Rice Husk Ash; Brackish Water; Iron (Fe) and Manganese (Mn).

\section{PENDAHULUAN}

Zeolit juga merupakan mineral yang memiliki rongga atau pori yang dapat melakukan filtrasi, Dimana zeolit memiliki pori- pori yang cenderung lebih kecil sehingga dapat melakukan filtrasi yang bersifat polar (Fish W et al, 2017). Mineral zeolit terbentuk dari tetrahedral $(\mathrm{Si}, \mathrm{Al}) \mathrm{O}_{4}$ yang saling berhubungan dengan penggunaan bersama atom hidrogen. Zeolit biasanya banyak terdapat didalam abu sekam padi (Furqoni, 2015). Hasil penelitian sebelumnya telah di buktikan bahwa di dalam abu sekam padi mengandung kadar silika yang cukup tinggi yaitu $87 \%$ - $97 \%$ yang dapat dimanfaatkan sebagai bahan dalam pembuatan zeolit yang digunakan untuk proses penjernihan air (Furqoni, 2015).

Air sungai yang terdapat di Tanjung Jabung Barat merupakan air payau dimana memiliki sifat fisika kimia air berwarna coklat kehitaman dengan kadar logam Fe 2,32 mg/l dan Mn 0,0307 mg/l dengan kadar air tersebut perlu adanya cara untuk menurunkan kadar supaya mendapatkan air yang layak untuk digunakan oleh masyarakat. Air payau berwarna coklat kehitaman yang mengandung kadar garam yang cukup tinggi dapat mengganggu metabolisme yang terjadi di dalam tubuh manusia. Penggunaan air payau untuk kebutuhan air minum dapat menyebabkan seseorang terkena penyakit 
perut seperti diare. Sedangkan bila digunakan untuk kebutuhan sehari-hari seperti mandi, dapat memicu munculnya penyakit kulit, seperti gatal-gatal (Agustina, 2015).

Berdasarkan pemeriksaan kadar logam diatas makan perlu adanya penurunan kadar logam besi (Fe) dan mangan $(\mathrm{Mn})$ yang dilakukan dengan metode spektrofotometri serapan atom (AAS). Selanjutnya adsorben zeolit dari abu sekam padi dianalisis dengan menggunakan Fourier Transform Infra Red (FTIR) dan X-ray diffraction (XRD). Penelitian ini bertujuan untuk mengetahui karakteristik zeolit dari abu sekam padi dan efektivitas adsorpsi logam $\mathrm{Fe}$ dan $\mathrm{Mn}$ air payau sungai serdang.

\section{METODE}

Penelitian ini merupakan penelitian eksperimental yang bertujuan untuk mengetahui abu sekam padi dapat digunakan dalam pembuatan zeolit untuk proses penjernihan air dan menurunkan kadar logam besi $(\mathrm{Fe})$ dan mangan (Mn). Penelitian ini dilakukan dengan cara pencampura natrium silikat dan natrium aluminat hingga diperoleh serbuk zeolit. Karakteristik zeolit dilakukan menggunakan menggunakan Fourier Transform Infra Red (FTIR) dan X-ray diffraction (XRD). Selanjutnya, analisa kadar logam setelah proses penjernihan air menggunakan Spektrofotometri Serapan Atom (SSA/AAS).

\section{Pembuatan Abu Sekam Padi}

Proses persiapan abu sekam padi berlangsung alami yaitu sekam padi dibersihkan dari kotoran dengan cara dicuci dengan aquadest, kemudian dikeringkan, sekam padi bersih dan kering dibakar menggunakan kaleng cat sehingga diperoleh arang sekam padi berwarna hitam.

\section{Pembuatan Natrium Silikat}

Abu sekam padi berwarna hitam sebanyak 30 gram ditambah dengan 30gram $\mathrm{NaOH}$ di abukan pada suhu $700^{\circ} \mathrm{C}$ selama 4 jam dalam tanur maka diperoleh abu sekam padi berwarna putih. Abu sekam padi dilarutkan dengan aquadest $100 \mathrm{~mL}$, kemudian disaring dengan kertas saring. Filtrat yang dihasilkan merupakan larutan silikat (Pranjoto Utomo dan Isti Yunita, 2014).

\section{Pembuatan Natrium Aluminat}

Natrium aluminat dibuat dengan melarutkan 30 gram $\mathrm{NaOH}$ dilarutkan dalam $50 \mathrm{~mL}$ aquadest. Selanjutnya ditambahkan 30 gram $\mathrm{Al}_{2} \mathrm{O}_{3}$ sedikit demi sedikit disertai pengadukan dan diencerkan hingga 50 $\mathrm{mL}$ (Era L, 2016)

\section{PembuatanZeolit}

Larutan I dan Larutan II dicampurkan kemudian diaduk dengan magnetik stirrer selama 2 jam pada suhu kamar. Selanjutnya sampel disaring dengan kertas saring. Sampel kemudian dikeringkan pada suhu $100^{\circ} \mathrm{C}$ selama 2 jam dan dianalisis dengan menggunakan FT-IR dan XRD (Era L, 2016).

\section{Proses Penjernihan Air Payau}

Tabel 1. Proses penjernihan air payau

\begin{tabular}{c|c|c}
\hline No & Percobaan I & Percobaan II \\
\hline 1. & Air & Air \\
\hline 2. & Zeolit & Abu sekam padi \\
\hline 3. & & Batu Koral \\
\hline 4. & & Arang Batok \\
\hline 5. & & Pasir \\
\hline 6. & & Ijuk \\
\hline
\end{tabular}

\section{Pengujian Logam}

Menggunakan alat Spektrofotometri Serapan Atom yang bertujuan untuk melihat kadar yang ada didalam air payau sungai Serdang.

\section{HASIL DAN PEMBAHASAN}

Pada analisa menggunakan FTIR untuk mengetahui gugus fungsi silika dan alumina dalam range $4000-600 \mathrm{~cm}^{-1}$. Hasil analisa diperoleh gugus fungsi :

Tabel 2. Hasil Uji FTIR

\begin{tabular}{|c|c|c|c|}
\hline \multirow[t]{2}{*}{ NO } & \multirow{2}{*}{$\begin{array}{l}\text { Bilangan gelombang } \\
\text { Berdasarkan Literatur }\end{array}$} & \multicolumn{2}{|c|}{ Hasil Uji FTIR Zeolit } \\
\hline & & $\begin{array}{c}\text { Bilangan } \\
\text { gelombang yang } \\
\text { didapat }\end{array}$ & $\begin{array}{l}\text { Analisa Gugus } \\
\text { Fungsi }\end{array}$ \\
\hline 1. & $3200-3700\left(\mathrm{~cm}^{-1}\right)$ & $3261\left(\mathrm{~cm}^{-1}\right)$ & $\begin{array}{c}\mathrm{Si}-\mathrm{OH}, \mathrm{Si}- \\
\mathrm{H}_{\text {stretch, }}, \mathrm{Al}-\mathrm{OH}\end{array}$ \\
\hline 2. & $800-2200\left(\mathrm{~cm}^{-1}\right)$ & $868-991\left(\mathrm{~cm}^{-1}\right)$ & $\begin{array}{c}\text { Si- } 0 \text {, Si- } \mathrm{H}_{\text {bend, }} \\
\text { Al- } 0\end{array}$ \\
\hline 3. & $650-750\left(\mathrm{~cm}^{-1}\right)$ & $706\left(\mathrm{~cm}^{-1}\right)$ & $\mathrm{Na}-\mathrm{X}$ \\
\hline
\end{tabular}

Tabel 3. Hasiluji XRD Aluminium Oksida $\left(\mathrm{Al}_{2} \mathrm{O}_{3}\right)$

\begin{tabular}{l|l|l|}
\hline \multicolumn{1}{c|}{ Sudut $2 \theta$} & \multicolumn{1}{|c|}{ Jarak d } & Intensitas (\%) \\
\hline 21.5350 & 4,12654 & 11,48 \\
\hline 32,3395 & 2,76833 & 97,96 \\
\hline 36,4130 & 2,46745 & 37,34 \\
\hline 37,8700 & 2,37580 & 100,00 \\
\hline 45,2885 & 2,00239 & 21,37 \\
\hline 57,0386 & 1,61468 & 12,51 \\
\hline 67,1018 & 1,39491 & 66,68 \\
\hline
\end{tabular}


Tabel 4. Hasil Uji XRD Sodium Silicat $\left(\mathrm{Na}_{2} \mathrm{SiO}_{2} \mathrm{H}_{2} \mathrm{O}\right)$

\begin{tabular}{|l|l|l|}
\hline \multicolumn{1}{|c|}{ Sudut $2 \theta$} & \multicolumn{1}{|c|}{ Jarak d } & Intensitas (\%) \\
\hline 21,5350 & 4,12654 & 11,48 \\
\hline 33,4542 & 2,67860 & 53,60 \\
\hline 45,2885 & 2,00239 & 21,37 \\
\hline 67,1018 & 1,39491 & 66,68 \\
\hline
\end{tabular}

Tabel 5. Hasil uji kadar zat kadar logam air

\begin{tabular}{|c|c|c|c|c|c|c|}
\hline \multirow[b]{2}{*}{ Sampel } & \multicolumn{2}{|c|}{ Kadar Arral } & \multicolumn{2}{|c|}{ Kadar Akhir } & \multicolumn{2}{|c|}{$\begin{array}{l}\text { \% Efesiensi } \\
\text { Penyerapan }\end{array}$} \\
\hline & $\begin{array}{c}\mathrm{Fe} \\
(\mathrm{mg} / \mathrm{L})\end{array}$ & $\begin{array}{c}\text { IIn } \\
\text { (mgl) }\end{array}$ & $\begin{array}{c}\mathrm{Fe} \\
(\mathrm{mg} \mathrm{L})\end{array}$ & $\begin{array}{c}\text { IIn } \\
\text { (mg } \mathrm{g} \text { ) }\end{array}$ & $\begin{array}{c}\mathrm{Fe} \\
(\mathrm{mgl})\end{array}$ & $\begin{array}{c}\text { VIn } \\
\text { (mg } \mathrm{L})\end{array}$ \\
\hline$P$ & 2,32 & 0,0307 & 0,1672 & $<0,01$ & $96,71 \%$ & $98,23 \%$ \\
\hline
\end{tabular}

\section{Pembahasan}

Penelitian ini dilakukan untuk proses penjernihan air payau sungai Serdang dari zeolit yang berbahan dasar abu sekam padi. Abu sekam padi hasil pemanasan kemudian dilebur bersama $\mathrm{NaOH}$ untuk membentuk larutan natrium silikat. Penggunaan $\mathrm{NaOH}$ berfungsi sebagai aktivator selama proses peleburan. Proses sintesis natrium silikat dilakukan dengan furnace pada suhu $700^{\circ} \mathrm{C}$ yang bertujuan untuk menghilangkan komponen organik yang masih ada, dengan reaksi kimia natrium silikat yaitu :

$\mathrm{SiO}_{2}+2 \mathrm{NaOH} \rightarrow \mathrm{Na}_{2} \mathrm{SiO}_{3}+\mathrm{H}_{2} \mathrm{O}$

Selanjutnya pembuatan natrium aluminat mengguakan $\mathrm{NaOH}$ dilarutkan dengan akuades ditambahkan $\mathrm{Al}_{2} \mathrm{O}_{3}$ makater bentuklah natrium aluminat yang merupakan sumber Al untuk zeolite sintesis (Era L, 2016).

$$
\mathrm{Al}_{2} \mathrm{O}_{3}+2 \mathrm{NaOH} \rightarrow 2 \mathrm{NaAlO}_{2}+\mathrm{H}_{2} \mathrm{O}
$$

Campuran silika dan alumina kemudian diaduk menggunakan magnetic stirrerdalam suhu kamar tujuanya untuk menyempurnakan terjadinya polimerisasi ion-ion pembentuk zeolit. Selanjutnya, sampel dikeringkan menggunakan oven pada suhu $100^{\circ} \mathrm{C}$ bertujuan untuk menghilangkan kadar air yang terdapat pada sampel. Reaksi yang terjadi saat peleburan adalah (Andarini $\mathrm{N}$ et al, 2018).

$\mathrm{NaAlO}_{2}+\mathrm{Na}_{2} \mathrm{SiO}_{3} \rightarrow \mathrm{NaSiO}_{3} \mathrm{Al}_{2} \mathrm{O}_{2}(\mathrm{OH}) . \mathrm{H}_{2} \mathrm{O}$
Pada analisa menggunakan FTIR untuk megetahui gugus fungsi silika dan alumina dalam range 4000-600 $\mathrm{cm}^{-1}$. Didapatkan Hasil analisa gugus fungsi yaitu $\mathrm{Si}-$ $\mathrm{OH}, \mathrm{Si}-\mathrm{H}$ stretch, Si-O, Si-Hbend, Al-OH, Al-O, dan Na$\mathrm{X}$.

Hasil analisa XRD zeolit terdapat dua senyawa yaitu Alumunium Oksida dan Natrium silikat. Hasil tersebut menunjukkan puncak tertinggi senyawa alumunium oksida terdapat pada puncak $2 \theta=37,8700^{\circ}$ $\left(\begin{array}{ll}d=37,8700 & \AA\end{array}\right), \quad$ Hasil penelitian sebelumnya menunjukkan bahwa puncak Natrium silikat dapat dilihat dari puncak tertinggi $2 \theta=67,1018^{\circ}$ $(\mathrm{d}=1,39491 \AA)$ berdasarkan hasil analisa XRD menunjukkan bahwa zeolit hasil sintetis mirip dengan zeolit A (Nikmah S, 2008).

Dimana zeolit dapat menyerap warna pada sampel air dan mengalami proses pertukaran ion atau penangkapan kation pada rongga-rongga kosong yang ada pada zeolit. Selain itu, Zeolit juga dapat mempercepat proses pengendapan partikel yang ada di air dan mampu menyaring molekul dengan ukuranukuran tertentu (Dur S, 2018). Percobaan I yang terdiri dari komponen Abu sekam padi dan zeolit menunjukkan bahwa penggunaan abu sekam padi bisa digunakan dalam proses penyaringan sehingga dapat menjernihkan air payau tetapi jika abu sekam padi tidak dibakar dan diolah secara sempurna dapat menyebabkan abu ikut tersaring kedalam air dan menyebabkan air menjadi terkontaminasi. Percobaan I yang terdiri dari komponen abu sekam padi, zeolit dan media penyaring didapatkan bahwa proses penyaringan menggunakan media penyaring mampu menurunkan kadar kekeruhan dan warna.

Hasil uji kimia air menggunakan Spektrofotometri Serapan Atom didapatakan hasil kadar $\mathrm{Fe}$ sebelum dilakukan proses penyaringan yaitu $2,32 \mathrm{mg} / \mathrm{l}$, sedangkan setelah dilakukan proses penyaringan didapatkan hasil kadar Fe pada percobaan yang terdiri dari air dan zeolit media penyaringan yaitu $0,1672 \mathrm{mg} / \mathrm{l}$, hal tersebut menunjukkan adanya kandungan silika yang mampu mengikat kadar besi pada air yang secara umum media tersebut dinyatakan efektif dalam menurunkan logam Fe yang memenuhi baku mutu sesuai Permenkes No.32/MENKES/PER/IV/2017 yakni konsentrasi maksimum Besi adalah 1,0 mg/l. Tujuan dari penurunan kadar $\mathrm{Fe}$ pada air yaitu untuk mengatasi berbagai masalah seperti korosif pada pipa, mengotori bak, wastafel, kloset, timbulnya wana, bau, dan rasa serta menyebabkan iritasi pada mata, kulit dan merusak dinding usus (Purwonugroho N, 2013).

Hasil kadar Mn sebelum dilakukan proses penyaringan yaitu $0,0307, \mathrm{mg} / \mathrm{l}$, sedangkan setelah dilakukan proses penyaringan didapatkan hasil penurunan kadar $\mathrm{Mn}$ terdiri dari air zeolit media penyaring yaitu $<0,01 \mathrm{mg} / \mathrm{l}$, hal tersebut menunjukkan adanya kandungan silika yang mampu mengikat kadar 
Mn yang secara umum media tersebut dinyatakan efektif dalam menurunkan kadar logam mangan pada air payau serta memenuhi baku mutu sesuai Permenkes No.32/MENKES/PER/IV/2017 yakni konsentrasi maksimum mangan adalah $0,5 \mathrm{mg} / \mathrm{l}$. Media filter zeolit ini merupakan senyawa dengan kation aktif yang bergerak pada umumnya bertindak sebagai penukar ion, sedangkan keberadaan atom alumunium di dalam zeolit akan menyebabkan memiliki muatan negatif yang menyebabkan zeolit mampu mengikat, zeolit berfungsi sebagai penukar ion dan adsorben dalam pengolahan air (Purwonugroho N, 2013). Tujuan dari penurunan kadar Mn pada air yaitu untuk mengatasi berbagai masalah kesehatan salah satunya kontaminan anorganik yang dapat menyebabkan penurunan kadar hemoglobin, neurotoksisitas dan rasa tidak enak jika konsentrasi Mn dalam air yang dikonsumsi tinggi. Mangan juga dapat merusak pakaian dan menyebabkan noda berwarna hitam kecoklatan (J. M. Amin, 2015).

\section{SIMPULAN}

Berdasarkan hasil penelitian tersebut dapat disimpulkan bahwa :

1. Zeolit yang terbuat dari abu sekam padi adalah zeolit $\mathrm{A}\left(\mathrm{Na}_{2} \mathrm{O} . \mathrm{Al}_{2} \mathrm{O}_{3} .2 \mathrm{SiO}_{2} .4,5 \mathrm{H}_{2} \mathrm{O}\right)$

2. Zeolit dari abu sekam padi dapat digunakan :

a. Proses penjernihan yang dihasilkan dapat menurunkan kadar kekeruhan dalam air payau sungai Serdang.

b. Untuk menurunkan kadar logam Mn sekitar 98,23 $\%$ dan Fe sekitar 96,71\% .

\section{DAFTAR PUSTAKA}

Fish W, Jabon P, Utama MP, Kusdarwati R, Sahidu M. Pengaruh Penggunaan Filtrasi Zeolit dan Arang Aktif terhadap Penurunan Logam Berat Timbal ( $\mathrm{Pb}$ ) Air Tambak Kecamatan Jabon , Sidoarjo Influence of Zeolites and Carbon Filtration to decline Heavy Metal Lead ( $\mathrm{Pb}$ ) in. J Mar Coast Sci. 2017;6(1).

Furqoni IY. Adln-perpustakaan universitas airlangga [Internet]. 2015. Available from: http://repository.unair.ac.id/68229/3/Fis.S.40.17 . Fur.p - JURNAL.pdf

Agustina. air payau. 2015. p. 4-27.

Pranjoto Utomo isti yunita. Sintesis Zeolit Dari Abu Sekam Padi Pada Temperatur Kamar. 2014. 1-39 p.

Era L. Zeolit sintesis dari sekam padi dan aplikasinya dalam menurunkan kadar ion Fe (II) pada air gambut. JKK. 2016;5(4).

Andarini N, Lutfia Z dkk. Sintesis Zeolit A dari Abu Terbang ( Fly Ash ) Batubara Variasi Rasio Molar Si / Al Synthesis of Zeolite A From Coal Fly Ash with Variation of $\mathrm{Si} / \mathrm{Al}$ Molar Ratio. 2018;19(2):105-10.
Nikmah S. Pengaruh Waktu Dan Perbandingan Si/Al Terhadap pembentukan Zeolit Dari Abu Dasar Bebas Karbon Dari PLTU PT.Ipmomi Dengan Metode Hidrotermal. 2008;7(1):42-52.

Dur S. Utilization Of Zeolits For Water Filing. Mat dan Terap. 2018;4(2):45-55.

Purwonugroho N. Keefektifan Kombinasi Media Folter Zeolit dan Karbon Aktif Dalam Menurunkan Kadar Besi (Fe) dan Mangan (Mn) Pada Air Sumur. 2013;11.

J.M.Amin. Penurunan Kadar Besi dan Mangan Terlarut dalam Air Payau Melalui Proses Oksidasi Menggunakan Kalium Permanganat. Lahan Suboptimal. 2015;4(1):38-46. 